\title{
Interfacial control on microstructure, morphology and optics of beta-Agl nanostructures fabricated on sputter-disordered Ag-Sn bilayers
}

\author{
D. Bharathi Mohan ${ }^{1}$, C. S. Sunandana ${ }^{2}$ \\ ${ }^{1}$ SEG-CEMUC-Department of Mechanical Engineering, University of Coimbra, Coimbra, Portugal; dhanabharathi@yahoo.com \\ ${ }^{2}$ School of Physics, University of Hyderabad, Hyderabad, India; csssp75@yahoo.com
}

Received 26 October 2009; revised 7 December 2009; accepted 10 February 2010.

\begin{abstract}
We report for the first time a non-template based facile growth of hexagonal $(\beta)$ Agl nanorods and nanoplates easily fabricated by rf magnetron sputtering on $\mathrm{Ag} / \mathrm{Sn}$ bilayers upon controlled iodination. The structural and morphological evolution of the $\beta$-Agl nanostructures is characterized by X-Ray Diffraction, Atomic Force Microscopy and optical spectroscopy. Sputtering induced disorder in precursor Ag films, high external stress and high defect concentrations at the Sn-Agl interface particularly facilitates the development of layered hexagonal structure of $\beta$-Agl nanostructures. Extremely sensitive room temperature optical absorbance involving evolution of $W_{1,2}$ and $W_{3}$ exciton transitions and emission spectra involving phonon replica corroborate the formation of $\beta$-Agl nanostructures with high defect concentrations, are aimed at improving the efficiency of photographic process and looking at microelectrodic and optoelectronic applications.
\end{abstract}

Keywords: Thin Films; Nanostructures; Crystal Structure; Optical Properties

\section{INTRODUCTION}

Motivated by an extreme mesoscopic ionic conductivity and superior photographic prowess, lately, many researchers have synthesized $\mathrm{Ag} / \mathrm{AgI}, \mathrm{AgI} / \gamma-\mathrm{Al}_{2} \mathrm{O}_{3}$ and $\mathrm{AgI}$ nanostructures in with controlled nano feature sizes and shapes by routes, including electrochemical, template-chemical, Ultrasonic pyrolysis, W/O microemulsions and solution methods[1-8]. These works, however, focused on the formation of highly stable $\beta$-AgI phase at room temperature [9] and its structural disordering, for- mation of highly conducting interfacial layers (i.e. $7 \mathrm{H}$ and 9R polytype of AgI with stacking fault arrangements), shape dependent properties and quantum confinement effects in nanorods. In this work, rf magnetron sputtering is exploited as an innovative technique to fabricate $\beta$-AgI nanostructures with different shapes-that could lead to miniaturized nanoscale opto-electronic devices [10]. Sputtering introduces structural disorder in Ag films while doping introduces extra disorder and external stress in the host and thus provides localized states for the nucleation of nanoparticles in an effectively kinetically controlled process [11]. To test and implement these ideas we fabricated $\mathrm{Ag} / \mathrm{Sn}$ bilayers by sputtering where an ultra thin layer $(\sim 3.5 \mathrm{~nm}$ to $14 \mathrm{~nm})$ of Sn serves as capping agent for Ag particles that introduces external stress at the $\mathrm{Ag} / \mathrm{Sn}$ interfaces eventually controlling nanomorphology of silver iodide. Moreover, doping could stabilize the crystal structure by strengthening the cation (or anion) sublattice of the ionocovalent semiconductor (CdS or AgI) and introducing a certain number of donors/acceptors in the forbidden gap of the host semiconductor thereby impacting the electrical and optical properties of the host semiconductor [12]. Sn -with valences 2 and 4- was chosen because it is a covalent metal and mixes well with Ag and could controls the iodization kinetics [13] enabling realization of desired optimized nanostructure even for a single $\mathrm{Ag} / \mathrm{Sn}$ ratio.

\section{EXPERIMENTAL METHODS}

$\mathrm{Ag} / \mathrm{Sn}$ bilayers were produced using rf magnetron sputtering (MagSput-1G2-RF-HOT-UPG) with Sn layer thickness varied from $3.5 \mathrm{~nm}$ to $14 \mathrm{~nm}$ while Ag layer thickness was fixed as $90 \mathrm{~nm}$. Silver (99.99\% purity) and tin $(99.99 \%$ purity) targets each $\sim 55 \mathrm{~nm}$ diameter and $\sim 3 \mathrm{~mm}$ thick was used for sputtering; the base pressure was always maintained as 1E-6 mbar. At first, Ag films were sputtered onto commercial float glass substrates 
under constant Ar flow rate and rf power of $20 \mathrm{sccm}$ and 10 Watt respectively. Then, $\mathrm{Sn}$ of $3.5 \mathrm{~nm}, 7 \mathrm{~nm}$ and $14 \mathrm{~nm}$ thick was successively deposited on Ag films with rf power: 5 Watt and Ar flow rate: $20 \mathrm{sccm}$. Substrate rotation and sputtering pressure were maintained as $10 \mathrm{RPM}$ and $1 \mathrm{E}-2 \mathrm{mBar}$ respectively. Thus, bi-layers of $\mathrm{Ag}(90 \mathrm{~nm}) / \mathrm{Sn}(3.5 \mathrm{~nm}), \mathrm{Ag}(90 \mathrm{~nm}) / \mathrm{Sn}(7 \mathrm{~nm})$ and $\mathrm{Ag}(90 \mathrm{~nm}) / \mathrm{Sn}(14 \mathrm{~nm})$ were fabricated and stored under vacuum in order to prevent surface oxidation. As grown $\mathrm{Ag}$ film and $\mathrm{Ag} / \mathrm{Sn}$ bilayers were iodized for selected durations ranging from $3 \mathrm{hrs}$ to 24 hours in a specially made jig [14]. AMBIOS XP-1 profilometer was used to measure the thickness and confirmed equal at different places for the homogeneity. X-ray diffraction patterns were obtained using INEL X-Ray Diffractometer (XRD) with $\operatorname{Co~} \mathrm{K}_{\alpha}\left(\lambda=1.78897 \mathrm{~A}^{0}\right)$ radiation. Atomic Force Microscopy (AFM) measurements were performed using SPA 400 operated in non-contact Dynamic Force Mode (DFM) mode. Optical absorption and photoluminescence studies were carried out using SHIMADZU UV-3101 and HITACHI: F-3010 Fluorescence spectrophotometers respectively.

\section{RESULTS AND DISCUSSIONS}

Figure 1 shows XRD patterns of $\mathrm{Ag}$ film and $\mathrm{Ag} / \mathrm{Sn}$ bilayers with increasing thickness of $\mathrm{Sn}$ layer. $\mathrm{Ag}$ is characterized by (111), (200), (220) and (311) planes corresponds to fcc lattice (JCPDS card No. 7440-22-4). $\mathrm{Ag} / \mathrm{Sn}$ bilayers exhibit similar pattern that obtained in undoped Ag despite increasing Sn layer thickness. However, intensities are decreased in $\mathrm{Ag}(90 \mathrm{~nm}) / \mathrm{Sn}$ $(3.5 \mathrm{~nm})$ could be due to the formation of quasi amorphous structure as due to $\mathrm{Sn}$ induced disorder in $\mathrm{Ag}$. Increasing Sn layer thickness from $7 \mathrm{~nm}$ to $14 \mathrm{~nm}$ increases the intensities with significant broadening attributed to smaller particle size possibly controlled by $\mathrm{Sn}$ atoms. Figure 2 shows the initial iodination of $\mathrm{Ag}$ $(90 \mathrm{~nm}) / \mathrm{Sn}(3.5 \mathrm{~nm})$ encourages both $\gamma$-AgI and $\beta$-AgI phases simultaneously. With $12 \mathrm{hrs}$ iodination, $\beta$-AgI phase became stronger while $\gamma$-AgI growth stops gradually. $\beta$-AgI phase develops gradually with increasing $\mathrm{Sn}$ layer thickness which is characterized by (002), (101), (102), (110), (103), (112), (202), (203), (105), (202), (303) and (006) crystal planes (JPCPDS card No. 75-1528). A facile growth of $\beta$-AgI phase is observed on $\mathrm{Ag}(90 \mathrm{~nm}) / \mathrm{Sn}$ (14 nm) could be due to the development of hexagonal and allied structures pointing to the role of $\mathrm{Sn}$ in modifying the stacking of atomic layers by introducing planar defects. Interestingly, (101), (102), (110), (103) and (112) reflections are predominant than from other planes possibly due to the formation of interfacial highly conducting layers i.e. $7 \mathrm{H}$ and 9R polytypes of AgI with the stacking fault arrangements. This is expectedly due to high external stress and high defect concentrations occurring especially

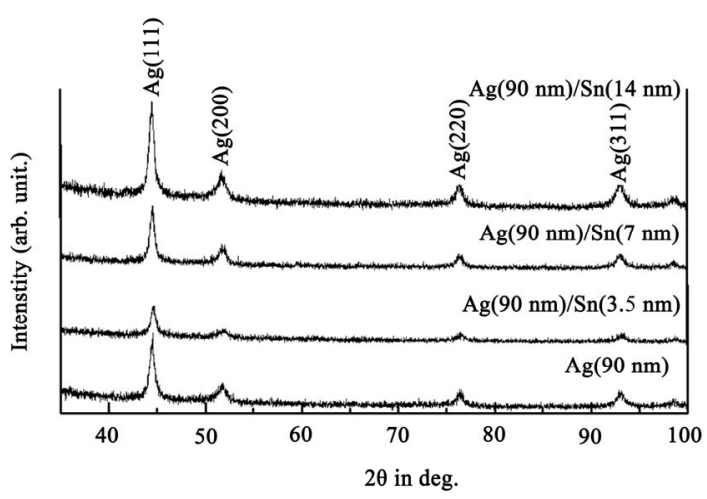

Figure 1. X-ray diffraction patterns of as deposited Ag and $\mathrm{Ag} / \mathrm{Sn}$ bilyers with increasing $\mathrm{Sn}$ layer thickness.

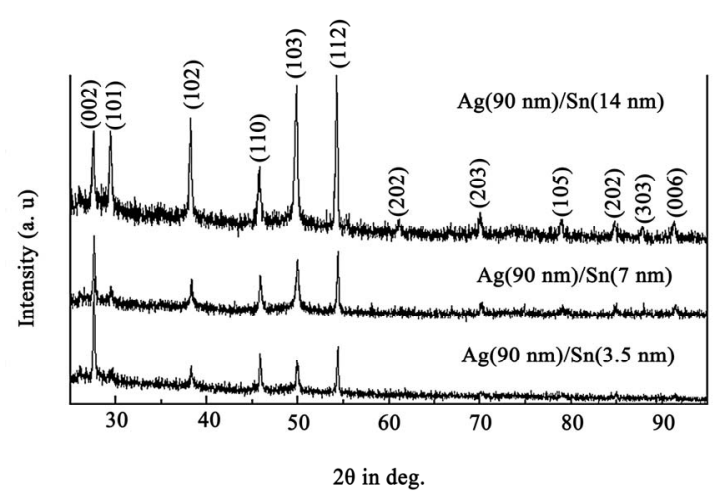

Figure 2. X-ray diffraction patterns of $\mathrm{Ag} / \mathrm{Sn}$ bilayers iodinated for $24 \mathrm{hrs}$.

at the Sn/AgI interface [15]. Formations of such polytypes are responsible for the enhanced mesoscopic room temperature ionic conductivity, by as much as four orders of magnitude, compared with bulk $\beta$-AgI [16]. Ultra thin $(\leq 20 \mathrm{~nm})$ undoped Ag produces $\gamma$-AgI while thick ( $\geq 20 \mathrm{~nm}$ ) Ag films encourage $\beta$-AgI growth [14] however not as neat a structure as observed in bilayers. Lattice parameter increases from $0.408 \mathrm{~nm}$ for undoped $\mathrm{Ag}$ to $0.409 \mathrm{~nm}$ for bilayers as well increases the lattice parameters of $a$ (from $0.458 \mathrm{~nm}$ to $0.460 \mathrm{~nm}$ ) and $c$ (from $0.751 \mathrm{~nm}$ to $0.752 \mathrm{~nm}$ ) of $\beta$-AgI. Increases in lattice parameters possibly reflects the difference in covalent radii of $\mathrm{Sn}(0.141 \mathrm{~nm})$ and $\mathrm{Ag}(0.134 \mathrm{~nm})$. Having deposited on glass and Ag surfaces, intrinsic strain could be different for Ag and Sn films as they possess tetragonal and cubic crystal structure respectively. Intrinsic strain determined for iodinated bilayers using Nelson-Reily Function (NRF) [17-18], exhibits zigzag patterns reflecting the presence of intrinsic strain in $\beta$-AgI structure (Figure 3).

Undoped Ag (Figure 4(a)) reveals an inhomogeneous surface with the particle size of about $20( \pm 1) \mathrm{nm}$. Particles are aggregated on the surface as due to lack of thermal energy during deposition. However, Sn layer evens the silver surface (Figure 4(b)) by filling pores and 


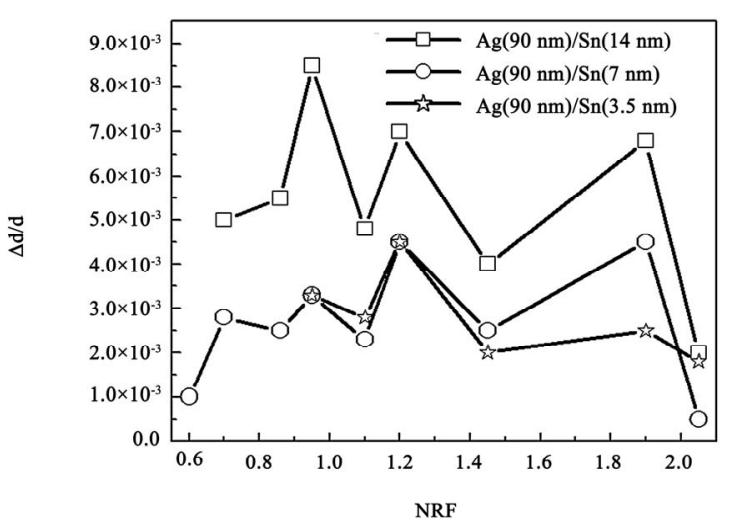

Figure 3. NRF function shows intrinsic strain of $\beta$-AgI phase increases with increasing Sn layer thickness.

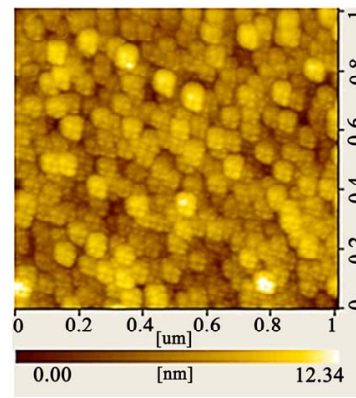

(a)

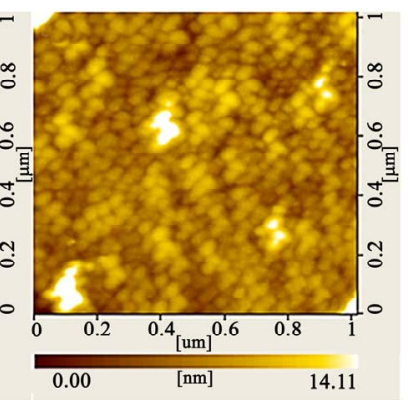

(b)
Figure 4. AFM shows surface morphology of (a) as deposited $\mathrm{Ag}(90 \mathrm{~nm})$ and (b) as deposited $\operatorname{Ag}(90 \mathrm{~nm}) / \mathrm{Sn}(7 \mathrm{~nm})$ bilayer.

covering boundaries due to its poor metallicity and higher solubility properties. Iodization of undoped $\mathrm{Ag}$ produces spherical shape of AgI particles with the size of about $\sim 150( \pm 1) \mathrm{nm}$ (Figure 5(a)) while Ag/Sn bilayers exhibit rod- and plate- shaped $\beta$-AgI particles. Moreover the length of rod increases from $437( \pm 1) \mathrm{nm}$ to $724( \pm 1) \mathrm{nm}$ upon increasing tin layer thickness from $3.5 \mathrm{~nm}$ to $7 \mathrm{~nm}$ (Figures 5(b) and 5(c)). Further increase of doping $(14 \mathrm{~nm})$ modifies the morphology from nanorods to nanoplatelets $(358 \times 353( \pm 1) \mathrm{nm})($ Figure 5(d)). Ag atoms need more iodine atoms in order to satisfy the condition $((\mathrm{Ag} / \mathrm{I}) \leq 1)$ for the $\beta-\mathrm{AgI}$ formation and that is indirectly supplied by $\mathrm{Sn}$ atoms through unstable $\mathrm{SnI}_{4}$ tetrahedra.

Uniodized Ag reveals uniodized Ag reveals a broad negative absorption around $320 \mathrm{~nm}$ due to Ag reflects the light particularly in opaque films [14,19]. No appreciable changes observed upon Sn doping except some variation in the shape and intensity. At an intermediate stage of iodization process, an evolution of optical absorption at $420 \mathrm{~nm}$ occurs due to the dipole forbidden $4 d^{10}-4 d^{9} 5 \mathrm{~s}$ transition in AgI allowed by the tetrahedral symmetry of $\mathrm{Ag}^{+}$ion in the wurtzite $\mathrm{AgI}$, attributed to $\mathrm{W}_{1,2}$ exciton besides a broad plasmon resonance $[14,19$, 20] at $500 \mathrm{~nm}$ arises due to residual $\mathrm{Ag}$ nanoparticles when the films are partially iodized consisting Ag-AgI nanocomposites. After $24 \mathrm{hrs}$ of iodization (Figure 6), plasmon resonance disappears while $\mathrm{W}_{1,2}$ exciton band enhances alongside a new peak developed at $330 \mathrm{~nm}$ due to spin-orbit split $\mathrm{I}^{-}$valence of the spin orbit interaction attributed to $\mathrm{W}_{3}$ exciton whose degeneracy is lifted due to strain field change at the crystallite surface [21]. These unusual observations are significant because the extremely sensitive room temperature optical absorption on $\beta$ - AgI has recorded the valence band degeneracy of which is lifted at room temperature which also happens to be the temperature at which iodization is carried out. Absorption becomes very intense, broad and red shifted upon increasing Sn doping [15]. The absorption increases as the length of the nanorods increases from 437 $( \pm 1)$ to $724( \pm 1) \mathrm{nm}$ however absorption band edge remain same. Surprisingly, absorption is four times intensive for AgI nanoplates as compared to AgI nanospheres. Absorption band is much wider for nanoplates. Band gap [14] decreases from $2.87 \mathrm{eV}$ to $2.83 \mathrm{eV}$ when $\beta$ - $\mathrm{AgI}$ particles change shape from nanospheres to nanoplatelets. The observed red shift arises from not only the different polymorphms of AgI nanoparticles but also due to an increase of Sn layer thickness.

Emission spectra of $24 \mathrm{hrs}$ iodized undoped $\mathrm{Ag}$ and $\mathrm{Ag} / \mathrm{Sn}$ bilayers were performed with the excitation wavelengths $325,335,345,350$ and $360 \mathrm{~nm}$. The photoinduced carrier radiative recombination rate is higher for the excitation wavelengths $345 \mathrm{~nm}$ and $350 \mathrm{~nm}$. Figure 7 shows the photoluminescence spectra excited at $350 \mathrm{~nm}$.

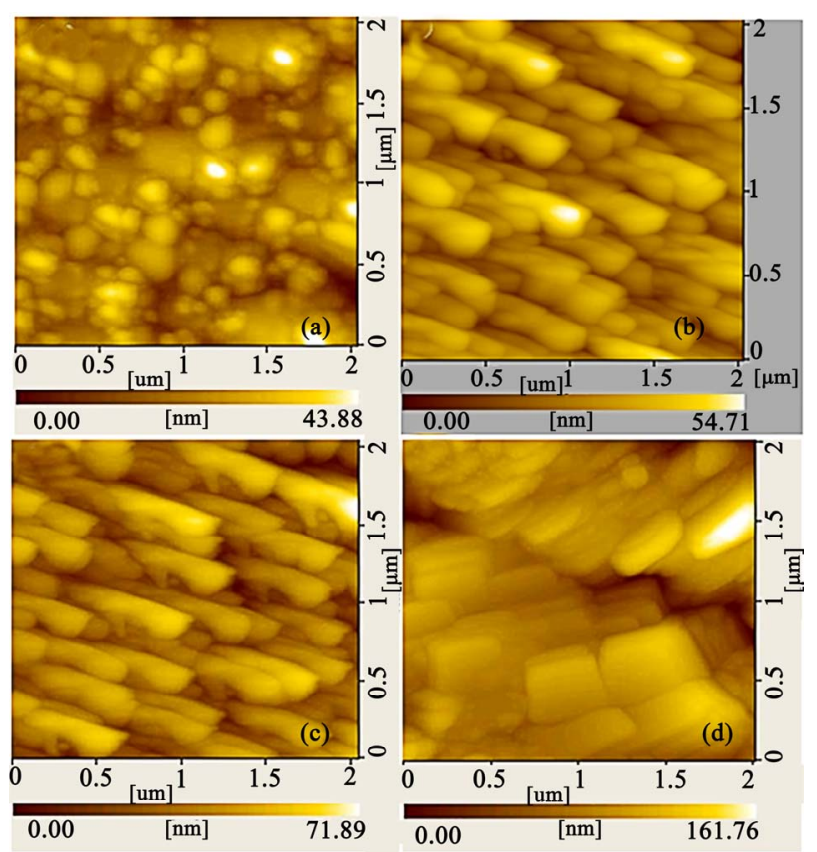

Figure 5. $\mathrm{AFM}$ of (a) $\mathrm{Ag}$, (b) $\operatorname{Ag}(90 \mathrm{~nm}) / \mathrm{Sn}(3.5 \mathrm{~nm})$, (c) $\operatorname{Ag}(90 \mathrm{~nm}) / \operatorname{Sn}(7 \mathrm{~nm})$ and (d) $\operatorname{Ag}(90 \mathrm{~nm}) / \operatorname{Sn}(14 \mathrm{~nm})$ iodinated for $24 \mathrm{hrs}$ 


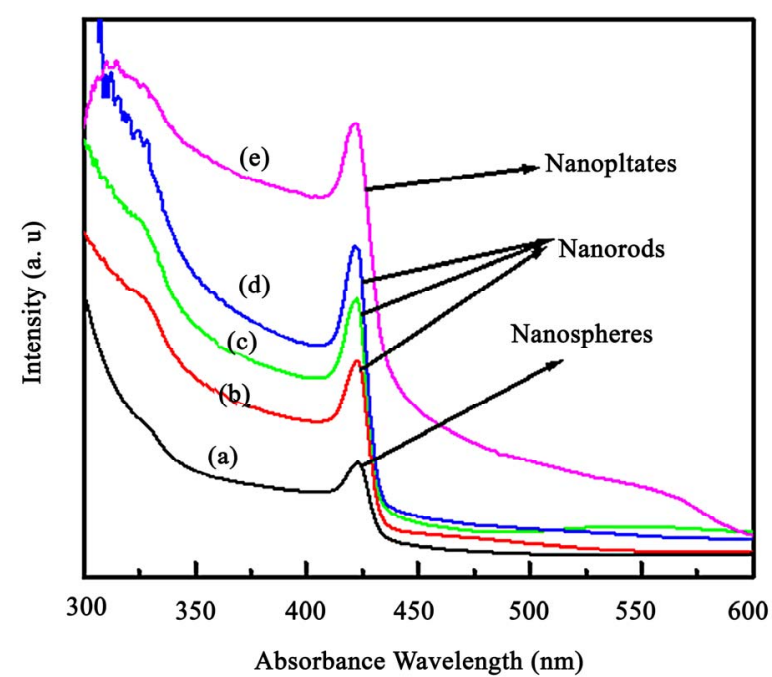

Figure 6. Optical absorbance of $24 \mathrm{hrs}$ iodinated (a) Ag; (b) $\operatorname{Ag}(90 \mathrm{~nm}) / \operatorname{Sn}(2 \mathrm{~nm}) ;($ c) $\operatorname{Ag}(90 \mathrm{~nm}) / \operatorname{Sn}(3.5 \mathrm{~nm}) ;(\mathrm{d})$ $\operatorname{Ag}(90 \mathrm{~nm}) / \operatorname{Sn}(7 \mathrm{~nm}) ;(\mathrm{e}) \operatorname{Ag}(90 \mathrm{~nm}) / \operatorname{Sn}(14 \mathrm{~nm})$ bilayers.

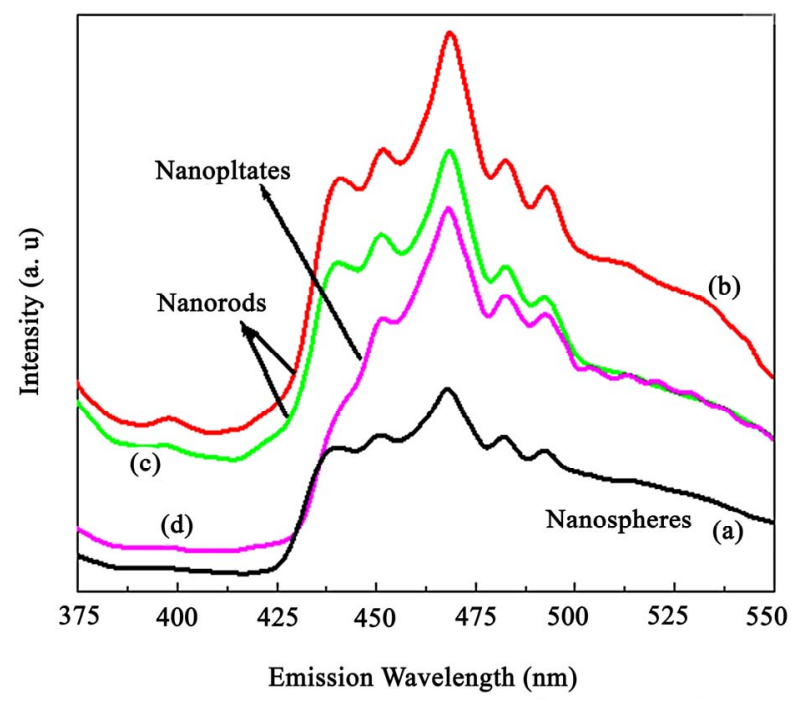

Figure 7. Emission spectra's of 24 hrs iodinated (a) $\mathrm{Ag}$; (b) $\operatorname{Ag}(90 \mathrm{~nm}) / \operatorname{Sn}(3.5 \mathrm{~nm}) ;($ c) $\operatorname{Ag}(90 \mathrm{~nm}) / \operatorname{Sn}(7 \mathrm{~nm}) ;(\mathrm{d})$ $\operatorname{Ag}(90 \mathrm{~nm}) / \mathrm{Sn}(14 \mathrm{~nm})$ excited at $350 \mathrm{~nm}$.

A sudden jump appears at $426 \mathrm{~nm}$ matching with the wavelength of absorbance of the $Z_{1,2}$ exciton [22]. The phonon emission accompanying PL (phonon replica) occurs at 437.8, 450.9, 467.0, 482.5 and $492.2 \mathrm{~nm}$ among them the most intense peak centered at $467.0 \mathrm{~nm}$. PL indicates photoexcited electrons at the conduction band edge do not recombine with holes immediately. Instead they undergo many transitions at the shallow trap states or intrinsic near-band edge states slightly below the conduction band involving exciton-phonon and multiphonon interactions. Intrinsic Frenkel defects and impurities could be involved in the formation of trapping states for the recombination. A fundamental reason for the enhancement of probabilities of phonon assisted optical transitions is the essential non-adiabaticity of exciton-phonon systems in quantum dots [23]. The recombination rate increases in nanorods while it is not too high in nanoplates. The relaxation process is apparently slow suggesting that the radiative life time of an exciton is smaller than the time of relaxation between the exciton energy levels. The enhanced trapping of the shallow and deep trap states and the limit of saturation can be visualized from the increase in the full width at half maximum of the inhomogeneously broadened subbands. Accordingly, maximum binding of almost all surface defect sites at low Sn concentration and quenching of radiative emission [24] at higher Sn concentration takes place. Thus, the strong PL features with red shift and multiphonon structure suggests a smaller radiative life time and higher recombination rate with respect to bulk. Reduction in intensity with increasing Sn concentrations saturating the initial traps could further quench the radiative emission, but did not affect the lifetimes effectively. Above a certain limit, Sn effectively blocks charge recombination and decreases the fluorescence quantum efficiency at higher concentrations but does not affect the decay characteristics at all concentrations. This is in accordance with the fact that the presence of higher valency dopant cations strongly reduces the iodination rate of silver under normal conditions. This work therefore has implications for opto-electronic applications.

\section{CONCLUSIONS}

A non-template based facile growth of hexagonal $(\beta) \mathrm{AgI}$ nanostructures were fabricated on $\mathrm{rf}$ magnetron sputtered $\mathrm{Ag} / \mathrm{Sn}$ bilayers upon controlled iodination. $\beta$-AgI phase was strongly observed on $\mathrm{Ag}(90 \mathrm{~nm}) / \mathrm{Sn}(14 \mathrm{~nm})$ as due to the development of hexagonal and allied structures that eventually proved the possibility of the formation of interfacial highly conducting layers i.e. $7 \mathrm{H}$ and $9 \mathrm{R}$ polytypes of AgI with the stacking fault arrangements. Shapes of the nanoparticles are tailored with respect to the amount of Sn doping onto $\mathrm{Ag}$ upon controlled iodization. Evolutions of $\mathrm{W}_{1,2}$ and $\mathrm{W}_{3}$ exciton transitions and phonon replica from absorption and emission spectra respectively corroborates the formation of $\beta$ - $\mathrm{AgI}$ nanostructures with high defect concentrations.

\section{ACKNOWLEDGEMENTS}

Sincere thanks are due to the University of Hyderabad for the award of research fellowship to D. Bharathi Mohan under UPE programme and for sanctioning publication charges for this paper.

\section{REFERENCES}

[1] Liang, C., Terabe, K., Tsuruoka, T., Osada, M., Hasegawa, T. and Aono, M. (2007) AgI/Ag heterojunction 
nanowires: Facile electrochemical synthesis, and enhanced ionic conductivity. Advanced Functional Materials, 17(9), 1466-1472.

[2] Lee, W., Yoo, H.-L. and Lee, J.-K. (2001) Template route toward a novel nanostructured superionic conductor film. Chemical Communications, 2001(24), 2530-2531.

[3] Guo, Y., Lee, J. and Maier, J. (2006) Preparation and characterization of AgI nanoparticles with controlled size, morphology and crystal structure. Solid State Ionics, 177(26-32), 2467-2471.

[4] Guo, Y.-G., Hu, Y.-S., Lee, J.-S. and Maier, J. (2006) High-performance rechargeable all-solid-state silver battery based on superionic AgI nanoplates. Electrochemistry Communications, 8(7), 1179-1184.

[5] El-Kouedi, M., Foss, C.A.Jr., Bodolosky-Bettis, S.A. and Bachman, R.E. (2002) Structural analysis of AgI and $\mathrm{Au} / \mathrm{AgI}$ nanocomposite films by powder x-ray diffraction: Evidence for preferential orientation. Journal of Physical Chemistry B, 106(29), 7205-7209.

[6] Xu, S. and Lee, Y. (2003) Different morphology at different reactant molar ratios: Synthesis of silver halide low-dimensional nanomaterials in microemulsions. Journal of Material Chemistry, 13(1), 163-165.

[7] Validzic, I.L., Jankovic, I.A., Mitric, M., Bibic, N. and Nedeljkovic, J.M. (2007) Growth and quantum confinement in AgI nanowires. Materials Letters, 61(16), 3522-3525.

[8] Validzic, I.L., Jokanovic, V., Uskokovic, D.P. and Nedeljkovic, J.M. (2008) Influence of solvent on the structural and morphological properties of AgI particles prepared using ultrasonic spray pyrolysis. Materials Chemistry and Physics, 107(1), 28-32.

[9] Chandra, S. (1981) Superionic solids: Principles and applications. North-Holland Publishing Company, Amsterdam.

[10] Mochizuki, S. and Fujishiro, F. (2003) Shallow and deep excited states of mesocopic structure in $\mathrm{AgI}-\gamma \mathrm{Al}_{2} \mathrm{O}_{3}$ composites. Physica Status Solidi (c), 0(2), 763-766.

[11] Mohan, D.B. and Sunandana, C.S. (2007) AgI nanostructure development in sputter-disordered and Al-doped Ag films probed by XRD, SEM, optical absorption and photoluminescence. Applied Physics A, 86(1), 73-82.

[12] Mohan, D.B. and Sunandana, C.S. (2004) Nanophases in mechanochemically synthesized AgI-CuI system: Struc- ture, phase stability and phase transition. Journal of Physics and Chemistry of Solids, 65(10), 1669-1677.

[13] Kuiry, S.C., Roy, S.K. and Bose, S.K. (1997) Influence of short circuiting on the kinetics and mechanism of iodide film growth on Ag and Cd-doped Ag. Metallurgical and Materials Transactions B, 28(6), 1189-1198.

[14] Mohan, D.B. and Sunandana, C.S. (2006) Iodization of rf sputter induced disordered $\mathrm{Ag}$ thin films reveals volume plasmon-exciton "transition". Journal of Applied Physics, 100(6), 4314

[15] Mohan, D.B. and Sunandana, C.S. (2005) Effect of Sn doping on the growth and optical properties of AgI nanoparticles. Journal Nanoscience and Nanotechnology, 5(9), 1-5.

[16] Guo, Y.J., Lee, J.-K. and Maier, J. (2005) AgI nanoplates with mesoscopic superionic conductivity at room temperature. Advanced Materials, 17(23), 2815-2819.

[17] Vook, R.W. and Witt, F. (1965) Structure and annealing behavior of metal films deposited on substrates near $80^{\circ} \mathrm{K}$ : I copper films on glass. Journal of Vacuum Science and Technology, 2(1), 49-57.

[18] Dayal, P.B., Mehta, B.R., Aparna, Y. and Shivaprasad, S.M. (2002) Surface-mediated structural transformation in CdTe nanoparticles dispersed in $\mathrm{SiO}_{2}$ thin films. $\mathrm{Ap}$ plied Physics Letters, 81(22), 4254-4256.

[19] Mohan, D.B., Sreejith, K. and Sunandana, C.S. (2007) Surface plasmon-exciton transition in ultra-thin silver and silver iodide films. Applied Physics B, 89(1), 59-63.

[20] Economou, E.N. (1969) Surface plasmons in thin films. Physical Review, 182(2), 539-554.

[21] Cardona, M. (1963) Optical properties of the silver and cuprous halides. Physical Review, 129(1), 69-78.

[22] Mochizuki, S. and Fujishiro, F. (2003) Structural, electrical and optical studies on AgI-anatase composites Journal of Physics: Condensed Matter, 15(29), 5057-5072.

[23] Kumar, P.S. (2002) Ionic and mesoscopic aspects of cation stabilized silver iodide. Ph.D Thesis, University of Hyderabad, Hyderabad, India.

[24] Kumar, P.S. and Sunandana, C.S. (2002) Steady-state photoluminescence characteristics of Sb-doped AgI thin films. Nano Letters, 2(9), 975-978. 